\title{
let-7a and its target, insulin-like growth factor 1 receptor, are differentially expressed in recurrent prostate cancer
}

\author{
BING TIAN ${ }^{1}$, NANNAN HUO ${ }^{1}$, MENG LI $^{1}$, YONG LI $^{1}$ and ZHONGZHOU HE ${ }^{2}$ \\ ${ }^{1}$ Department of Urology, Affiliated Xinhua Hospital of Dalian Medical University; ${ }^{2}$ Department of Urology, \\ The First Affiliated Hospital of Dalian Medical University, Dalian, Liaoning 116001, P.R. China
}

Received December 11, 2014; Accepted August 10, 2015

DOI: $10.3892 /$ ijmm.2015.2357

\begin{abstract}
Prostate cancer (PCa) is the most common malignancy in males worldwide. Approximately $30 \%$ of those patients who received radical prostatectomy developed clinical recurrence accompanied by elevated serum prostate-specific antigen levels. Although knowledge regarding the development of PCa has been significantly improved, the molecular mechanism underlying recurrence remains largely unknown. The objective of the present study was to identify the differentially expressed microRNAs (miRNAs) in recurrent PCa to explore the possible involvement of miRNAs in the relapse. The expression of $6 \mathrm{miRs}$ that have been previously reported to be downregulated in PCa stem cells were examined in a total of 32 recurrent and 36 non-recurrent $\mathrm{PCa}$ samples, and let-7a was substantially decreased in the recurrent PCa. Using the online prediction tools, let-7a was identified to virtually target insulin-like growth factor 1 receptor (IGF1R). IGF1R as a target of let-7a was subsequently validated using the luciferase assay. Exogenous expression of let-7a suppressed the expression of IGF1R, and reduced the proliferation of PCa cells by introducing apoptosis to the cells. In conclusion, the present data demonstrated a possible involvement of let-7a in the pathogenesis of recurrent $\mathrm{PCa}$, and it may be a potential target of the disease.
\end{abstract}

\section{Introduction}

Prostate cancer (PCa) is the most common non-skin malignancy in males worldwide (1). Approximately $80 \%$ of $\mathrm{PCa}$ patients are diagnosed at an early stage, and the disease is confined to the prostate, and therefore, radical prostatectomy (RP) is the treatment of choice for organ-confined prostate tumors (2). However, $\sim 30 \%$ of patients who received

Correspondence to: Dr Zhongzhou He, Department of Urology, The First Affiliated Hospital of Dalian Medical University, 222 Zhongshan Road, Dalian, Liaoning 116001, P.R. China E-mail: zhonghouhe006@163.com

Key words: let-7a, insulin-like growth factor 1 receptor, prostate cancer, proliferation, inducible nitric oxide synthase the surgical treatment developed tumor recurrence within 10 years postoperation (2). Presently, prognostic markers, such as the level of prostate-specific antigen, clinical stage and the grade of tumor (Gleason score), have been used to predict recurrence; however, they do not explain the interindividual variation in the clinical outcomes among the patients who received RP. Therefore, new biomarkers are required to identify the patients who are at a greater risk of developing recurrence following surgery.

MicroRNAs (miRNAs or miRs), 22 nucleotides in length, have emerged as one of the key factors of the regulatory network that regulates a wide spectrum of cellular activities, such as proliferation, apoptosis, migration and differentiation, by modulating the expression of target genes via binding to the seed sequence at the $3^{\prime}$ untranslated region (3'UTR) of target mRNAs, resulting in translational repression or mRNA degradation (3). In recent years, the function of miRs in human cancer has attracted increasing attention (4-6). Numerous studies have revealed the role of miRs in the development and progression in tumors by microarray assays $(7,8)$. The aberrant expression of miRs could be categorized into two classes: Upregulated and downregulated miRs. Certain miRs, known as tumor-suppressor miRs, in cancer have been shown to suppress the expression of oncogenes, leading to the inhibition of cancer cell proliferation $(9,10)$. While other highly expressed miRs, known as oncogenic miRs, in cancer have been shown to inhibit tumor-suppressor genes and promote tumor proliferation and metastasis $(11,12)$. Although specific miRs are overexpressed in cancer cells, the majority of cancer-related miRs are downregulated in tumors, indicating the fact that there are more tumor-suppressor compared to oncogenic miRs $(13,14)$. Microarray-based expression profiling analysis highlighted the critical role of miRNAs in the pathogenesis of PCa (14). However, the association between the miRNA expression and $\mathrm{PCa}$ recurrence remains largely unknown. To date, only a few studies have investigated miRNA expression and PCa recurrence following RP (15-20), showing that miRNAs, including miR-21, miR-221 and miR-222, are potential prognostic markers for recurrence.

Cancer stem cell (CSC) theory was initially introduced by Mackillop et al (21) and was validated in acute myeloid leukemia for the first time in 1997 (22). In this theory, the population of cancer cells retains a hierarchical system, and CSCs constitute a small part of tumor cells, which are 
characterized by their ability to seed new tumors. The CSC theory has been subsequently validated in a wide spectrum of human cancers, such as breast (23), brain (24), pancreatic (25) and liver cancer (26), and PCa (27). In PCa, CSCs are believed to be involved in regulating metastasis, relapse and therapy resistance (28-31).

Based on the above-mentioned evidence, we hypothesize that the differentially expressed miRNAs in the PCa stem cells may be responsible for the pathogenesis of the disease recurrence. To test the hypothesis, the expression levels of 6 candidate miRNAs that are differentially expressed in prostate CSCs were evaluated and compared based on microarray analysis in a previous study (32), and let-7a was substantially downregulated in recurrent compared with non-current PCa. let-7a was established as an effective biomarker to predict recurrence of the cancer.

\section{Materials and methods}

Patients. A total of 68 patients with histologically confirmed PCa by RP, including 32 recurrent and 36 non-recurrent cases, were recruited in the First Affiliated Hospital of Dalian Medical University, Department of Urology (Liaoning, China). The clinicopathological characteristics of the recurrent and non-recurrent patients are presented in Table I. Patients were followed up for $\geq 4$ years (defined as non-recurrent cases) or until prostate-specific antigen (PSA) recurrence (recurrence was defined as two consecutive serum PSAs $>0.2 \mathrm{ng} / \mathrm{ml}$ ). The study was approved by an internal institutional review board at Dalian Medical University. Patients were included into the study upon giving their written informed consent.

Total RNA isolation. Total RNA was isolated from 32 recurrent and 36 non-recurrent tissue samples using TRIzol reagent (Invitrogen Life Technologies, San Diego, CA, USA) according to the manufacturer's instructions. The purities and concentrations of RNA samples were determined spectrophotometrically using NanoDrop ND-2000c (Thermo Fisher Scientific, Inc., Wilmington, DE, USA). RNA integrity was examined using gel electrophoresis.

cDNA synthesis and reverse transcription-quantitative polymerase chain reaction $(R T-q P C R)$. To validate the differential expression of miR-143/145, let-7a, miR-200a, miR-10 and miR-17, RNA samples were isolated from a different set of 32 recurrent and 36 non-recurrent patients. For miRNA RT-qPCR experiments, equal amounts of total RNA from each sample were used for first-strand DNA (cDNA) synthesis using the TaqMan MicroRNA Reverse Transcription kit according to the manufacturer's instructions (Applied Biosystems, Foster City, CA, USA). The TaqMan Universal Master mix (Applied Biosystems) was used for the specific chromosome segment amplification, including TaqMan miR-143 (assay ID: 002249), miR-145 (assay ID: Hs03303169_pri), miR-200a (assay ID: 000502), miR-10 (assay ID: 000387), miR-17 (assay ID: 002308) and let-7a (assay ID: 000377) amplification kits that were obtained from Applied Biosystems. miRNA expression analysis by RT-qPCR was carried out using a Roche LightCycler 480 II real-time thermal cycler (Roche Diagnostics, Basel, Switzerland). miRNA expression data were normalized to RNU43. Relative miRNA
Table I. Clinicopathological characteristics of the subjects recruited in the study.

\begin{tabular}{lcc}
\hline $\begin{array}{l}\text { Clinicopathological } \\
\text { parameters }\end{array}$ & $\begin{array}{c}\text { Non-recurrent } \\
\text { cases }(\mathrm{n}=36)\end{array}$ & $\begin{array}{c}\text { Recurrent } \\
\text { cases }(\mathrm{n}=32)\end{array}$ \\
\hline $\begin{array}{l}\text { Age, years (range) } \\
\text { Pre-operative PSA }\end{array}$ & $66(49-77)$ & $65(45-75)$ \\
Mean ng/ml (range) & $22(1-86)$ & $45(18-148)$ \\
Gleason score, n (\%) & & \\
$\leq 6$ & $2(5.55)$ & $2(6.25)$ \\
7 & $16(44.44)$ & $7(21.88)$ \\
8 & $9(25.00)$ & $11(34.38)$ \\
9 & $5(13.89)$ & $9(28.13)$ \\
10 & $4(11.11)$ & $3(9.38)$ \\
Pathological tumor stage, $\mathrm{n}(\%)$ & & \\
pT2 & $4(11.11)$ & $3(9.38)$ \\
pT3a & $14(38.89)$ & $11(34.38)$ \\
pT3b & $10(27.78)$ & $15(46.88)$ \\
pT4 & $8(22.22)$ & $4(12.50)$ \\
Lymph node metastasis, $n(\%)$ & & \\
Positive & $8(22.22)$ & $11(34.38)$ \\
Negative & $28(77.78)$ & $22(68.75)$ \\
\hline
\end{tabular}

expression was calculated with the comparative $\Delta \mathrm{Ct}$-method $(\Delta \mathrm{Ct}$ sample $=\mathrm{Ct}$ sample $-\mathrm{Ct} \mathrm{RNU6B})$. The $2^{-\Delta \Delta \mathrm{Ct}}$ method was used to assess fold changes in miR expression between samples and controls. Mean $\mathrm{Ct}$ was determined from triplicate PCR experiments.

Cell culture. LNCaP cells, originally purchased from American Type Culture Collection (Manassas, VA, USA), were maintained in RPMI-1640 supplemented with $10 \%$ fetal bovine serum, $10 \mathrm{mmol} / \mathrm{l}$ Hepes, $50 \mathrm{U} / \mathrm{ml}$ penicillin and $50 \mathrm{mg} / \mathrm{ml}$ streptomycin (all from Invitrogen Life Technologies, Carlsbad, CA, USA). The cells were cultured in a $5 \% \mathrm{CO}_{2}$ humidified atmosphere at $37^{\circ} \mathrm{C}$, and genotypically characterized to support the authenticity of these cells, which was consistent with their origin.

miRNA mimics/inhibitors and transfection. Cells were transfected with $50 \mathrm{nmol} / 1$ of let-7a mimics or anti-let-7a inhibitors or Negative Control \#1 (Ambion, Austin, TX, USA) using DharmaFECT 3 Transfection reagent (Dharmacon, Inc., Lafayette, CO, USA). After 24, 48 and $72 \mathrm{~h}$ transfection, the cells were harvested and subjected to the 3-(4,5-dimethylthiazol-2-yl)-2,5-diphenyltetrazolium bromide (MTT) assay to evaluate the survivals, and sections of the cells harvested $48 \mathrm{~h}$ after transfection were also used for RT-qPCR, western blotting and the apoptosis assay.

Western blotting. Cells were lysed following preparation and determination of equal amounts of proteins. The proteins were separated on SDS-PAGE and later transferred to a PVDF membrane (Millipore, Billerica, MA, USA). For protein expression of insulin-like growth factor 1 receptor (IGF1R), 
$1 \mathrm{mg} / \mathrm{ml}$ goat polyclonal antibodies (Cat. no. ab4065; Abcam, Cambridge, MA, USA) was used and $\beta$-actin (Cat. no. ab6276; Abcam) served as a reference. For visualization, horseradish peroxidase-coupled secondary antibodies (Cat. no. ab6728; Abcam) and the ECL Plus kit (Pierce Biotechnology, Inc., Rockford, IL, USA) were used to develop the signals. For quantification of band intensity, ImageJ (http://imagej.nih. gov/ij/) (NIH, Baltimore, MD, USA) was used.

Luciferase assay. LNCaP3 cells were seeded at a density of $6 \times 10^{3}$ cells/well in a $96-$ well plate and incubated for $24 \mathrm{~h}$. The cells were co-transfected with wild-type or mutant IGF1R 3'UTR luciferase plasmid or Renilla luciferase plasmid and control miRNA, and the let-7a mimics using DharmaFECT DUO Transfection reagent (Dharmacon, Inc.). After $48 \mathrm{~h}$ of incubation, luciferase activity was assayed using the Steady-Glo Luciferase Assay System (Promega Corp., Madison, WI, USA). The Renilla luciferase activity was used as a control for transfection efficiency.

Apoptosis assay. Flow cytometry-based apoptosis was analyzed. At $48 \mathrm{~h}$ post-transfection, the LNCaP cells were harvested and resuspended in phosphate-buffered saline (PBS) and subsequently fixed in ethanol at room temperature overnight. The cells were washed with PBS and resuspended in staining solution $(50 \mathrm{mg} / \mathrm{ml}$ propidium iodide, $1 \mathrm{mg} / \mathrm{ml}$ RNase A and $0.1 \%$ Triton X-100 in PBS; all purchased from Invitrogen Life Technologies). The stained cells were subsequently analyzed for apoptosis with the Becton Dickinson Flow Cytometer (PT. Madagasi Brosa, Inc., Sumatera Utara, Indonesia).

MTT assay. LNCaP cells transfected with either NC or let-7a mimics, or let-7a inhibitor were plated on 96 -well plates at $1 \times 10^{4}$ cells/well. Viable cells were measured 24,48 and $72 \mathrm{~h}$ after transfection. Following incubation with MTT, the cells were lysed in $150 \mathrm{ml}$ of $100 \%$ dimethyl sulfoxide (both from Sigma-Aldrich, St. Louis, MO, USA) and UV-visible absorbance was read at $490 \mathrm{~nm}$ using the 96 -well plate reader. Each sample was run in triplicate.

Statistical analysis. Differences between each group were determined by the t-test or Mann-Whitney U test using Statistical SPSS software package 19.00 (IBM, Corp., Armonk, $\mathrm{NY}, \mathrm{USA}$ ). $\mathrm{P}<0.05$ was considered to indicate a statistically significant difference.

\section{Results}

Patient characteristics. A total of 32 recurrent and 36 non-recurrent tumors from RP were included in the study. The average age of the patients with recurrent PCa was 65 years, whereas those without recurrence had an average age of 66 years. All the participants recruited in the study were of Han ethnicity. The PSA level ranged from 18 to $148 \mathrm{ng} / \mathrm{ml}$ and 1 to $86 \mathrm{ng} / \mathrm{ml}$ in patients with and without recurrence, respectively. As expected, the mean pre-operative PSA level of recurrent patients was almost twice that of the non-recurrent patients ( 22 vs. $45 \mathrm{ng} / \mathrm{ml}$ ). The clinicopathological features, such as Gleason score, tumor stages and lymph node metastasis, are described in Table I.

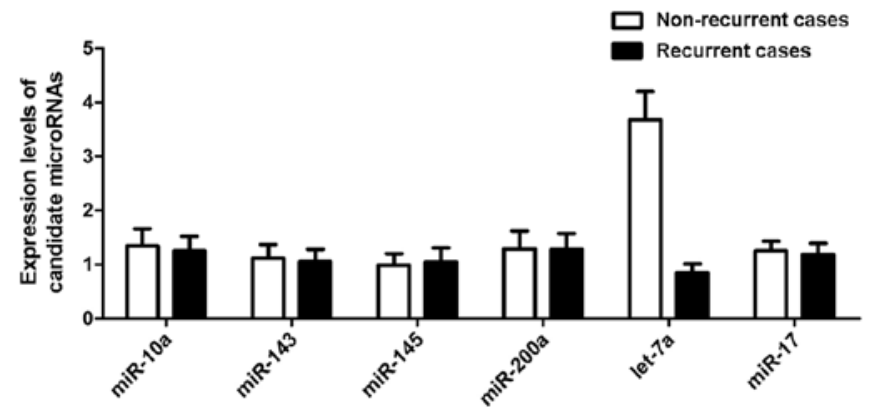

Figure 1. Expression levels of 6 candidate microRNAs (miRs) (miR-10a, miR-143, miR-145, miR-200a, let-7a, and miR-17) that have been reported to be downregulated in prostate cancer stem cells were determined using reverse transcription-quantitative polymerase chain reaction in 32 recurrent and 36 non-recurrent PCa samples.

\section{A}

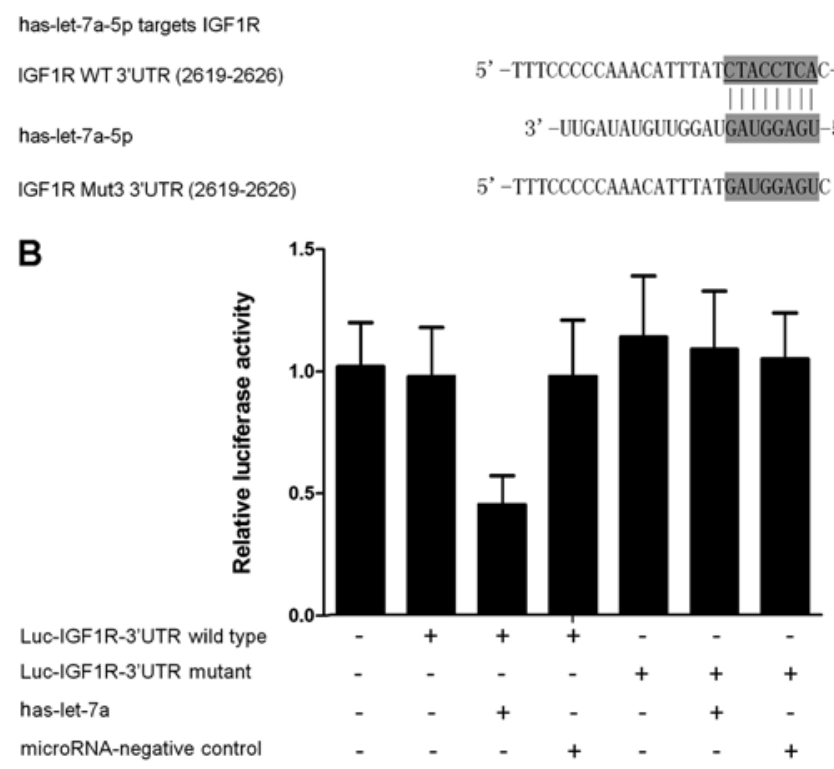

Figure 2. (A) Comparison of the wild-type or mutant $3^{\prime}$ untranslated region (3'UTR) of insulin-like growth factor 1 receptor (IGF1R) and mature let-7a sequence. (B) Luciferase assay showed that only the luciferase activity in LNCaP cells transfected with let-7a mimics and wild-type 3'UTR of IGF1R were significantly decreased.

Evaluation of miRNAs expressed in recurrent PCa. To evaluate the differentially expressed miRNAs in recurrent $\mathrm{PCa}$, 6 candidate miRNAs were selected that have been reported to be differentially expressed in PCa stem cells based on the miRNA microarray analysis, considering the significant role of CSCs in the pathogenesis of recurrent PCa. RT-qPCR was performed to examine the expression levels of the 6 candidate miRNAs in 32 recurrent and 36 non-recurrent case samples, and only 1 miRNA, let-7a, was significantly downregulated in the recurrent groups with all the other 5 miRNAs similarly expressed in the two groups, as shown in Fig. 1. Therefore, the following functional analysis was focused on let-7a.

Identification of the target gene of let-7a in PCa. To identify the potential target gene of let-7a in PCa, the online miRNA database (www.mirdb.org) was searched and IGF1R was found to be a potential target gene (Fig. 2A). Subsequently, 

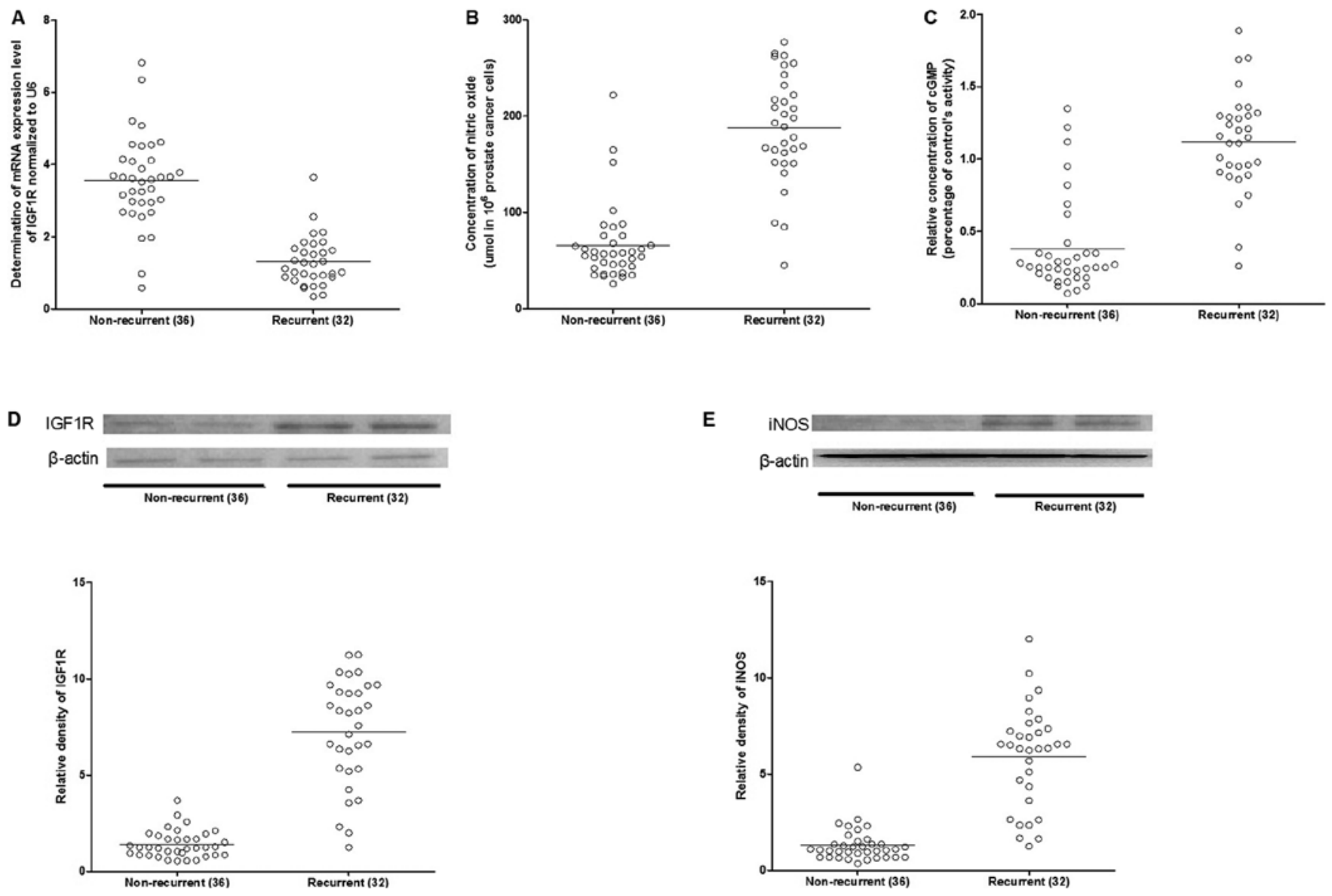

Figure 3. mRNA and protein expression level patterns in the recurrent and non-recurrent prostate cancer groups. (A) The mRNA expression level of insulin-like growth factor 1 receptor (IGF1R), (B) nitric oxide (NO) production, (C) cyclic guanosine monophosphate (cGMP) concentration, (D) protein expression level of IGF1R (upper: Western blotting; lower: Densitometry analysis) and (E) protein expression level of inducible nitric oxide synthase (iNOS) were significantly higher in the recurrent compared to the non-recurrent group (upper: Western blotting; lower: Densitometry analysis).

the wild-type of 3'UTR of IGF1R was subcloned and inserted into the vector that contained the luciferase gene, and the 'seed sequence' in the 3'UTR of IGF1R was replaced using site-directed mutagenesis (Fig. 2A). The results of the luciferase assay showed that the relative luciferase activities in the let-7a-overexpressing PCa cells transfected with wild-type 3'UTR of IGF1R were substantially lower than those cells transfected with mutant 3'UTR of IGF1R (Fig. 2B), suggesting that IGF1R was an effective target of let-7a with the 'seed sequence' in the 3'UTR acting as the binding site of the miRNA.

Assessment of protein and mRNA expression level patterns. To identify the miRNA-gene association in the recurrence of the disease, the mRNA and protein expression patterns in the recurrent and non-recurrent cases were assessed using RT-qPCR and western blotting. The mRNA and protein expression levels of IGF1R were significantly upregulated in the recurrent cases (Fig. 3). As a downstream effector of IGF1R, the expression level of inducible nitric oxide synthase (iNOS) was also increased in the recurrent cases (Fig. 3), and consistently, as the catalytic products of iNOS, the concentration of nitric oxide and cGMP were markedly higher in the recurrent compared to non-recurrent groups (Fig. 3).
Function of let-7a in PCa cells. To further characterize the role of let-7a, 'gain-of-function' analysis was performed by transfecting let-7a mimics. After $48 \mathrm{~h}$ transfection, the expression level of let-7a was $\sim 30$ times higher than those cells transfected with the negative controls (data not shown). As expected, exogenous overexpression of let-7a significantly downregulated the expression of IGF1R, as well as its downstream effector, iNOS, as shown in Fig. 4. The NO and cyclic guanosine monophosphate (cGMP) concentrations were much lower in the cells transfected with let-7a mimics compared to the controls (Fig. 4).

Toconfirmthefunctionoflet-7ainPCacells, 'loss-of-function' analysis was performed by transfecting anti-let-7a inhibitors. After $48 \mathrm{~h}$ transfection, the expression level of let-7a was $\sim 12$ times lower than those cells transfected with negative controls (data not shown). In line with the 'gain-of-function' result, the downregulation of let-7a significantly promoted the expression of IGF1R and iNOS. In addition, the concentrations of NO and cGMP were also enhanced by the inhibitors (Fig. 5).

Considering the significant role of the let-7a-IGF1RiNOS-NO-cGMP axis in the control of cellular proliferation, the effect of let-7a expression alternation on the growth of PCa cells was further evaluated, identifying that exogenous overexpression of let-7a substantially suppressed the proliferation of the cells, while inhibition of let-7a evidently promoted 

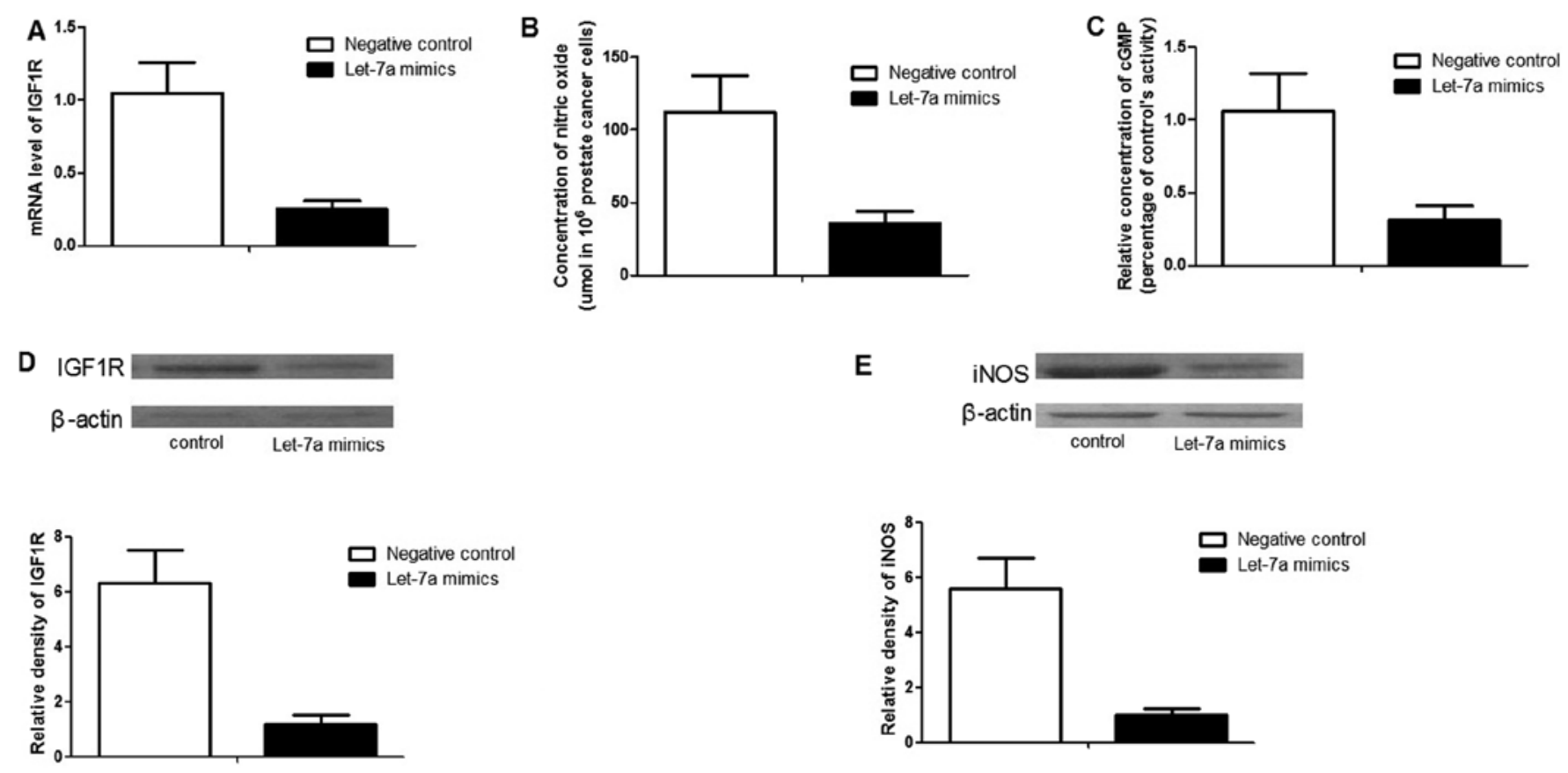

Figure 4. Function of let-7a in the prostate cancer cells. (A) The mRNA expression level of insulin-like growth factor 1 receptor (IGF1R), (B) nitric oxide (NO) production, (C) cyclic guanosine monophosphate (cGMP) concentration, (D) protein expression level of IGF1R (upper: Western blotting; lower: Densitometry analysis) and (E) protein expression level of inducible nitric oxide synthase (iNOS) were significantly higher in LNCaP cells transfected with negative control compared to the let-7a mimics (upper: Western blotting; lower: Densitometry analysis).
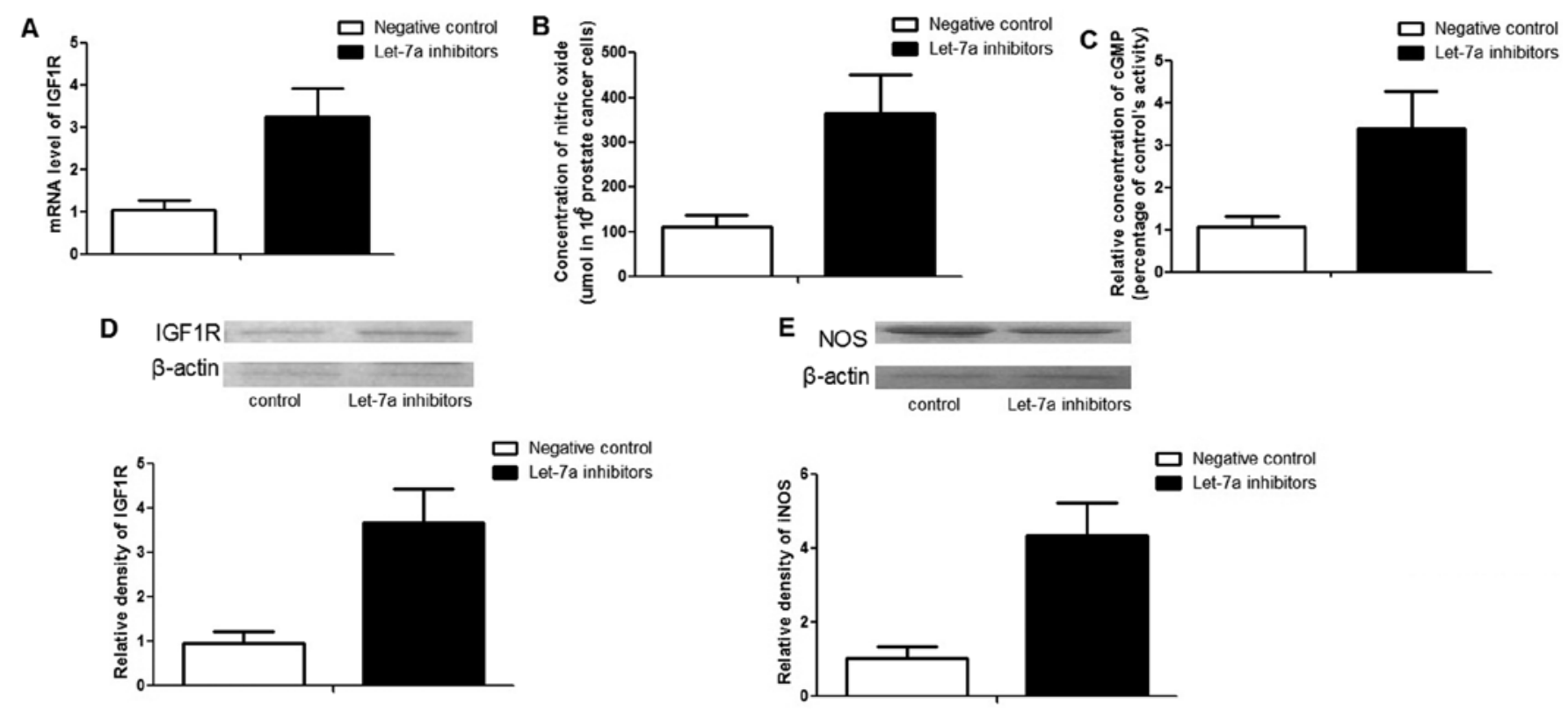

Figure 5. Confirming the function of let-7a in PCa cells using 'loss-of-function' analysis by transfection with anti-let-7a inhibitors. (A) mRNA expression level of insulin-like growth factor 1 receptor (IGF1R), (B) nitric oxide (NO) production, (C) cyclic guanosine monophosphate (cGMP) concentration, (D) protein expression level of IGF1R (upper: Western blotting; lower: Densitometry analysis) and (E) protein expression level of iNOS were significantly lower in LNCaP cells transfected with negative control compared to the let-7a inhibitors (upper: Western blotting; lower: Densitometry analysis).

the proliferation (Fig. 6). Additionally, flow cytometry analysis was used to explore the molecular mechanism underlying the proliferation-regulating effect, and exogenous overexpression of let-7a significantly introduced apoptosis to the LNCaP cells, while transfection with let-7a inhibitors reduced the apoptosis, as shown in Fig. 6.

\section{Discussion}

PCa is characterized by highly heterogeneous disease courses, and $\sim 30 \%$ of the PCa patients develop recurrence even following a successful surgical intervention or adjuvant therapy $(33,34)$. The most commonly used biomarkers to 

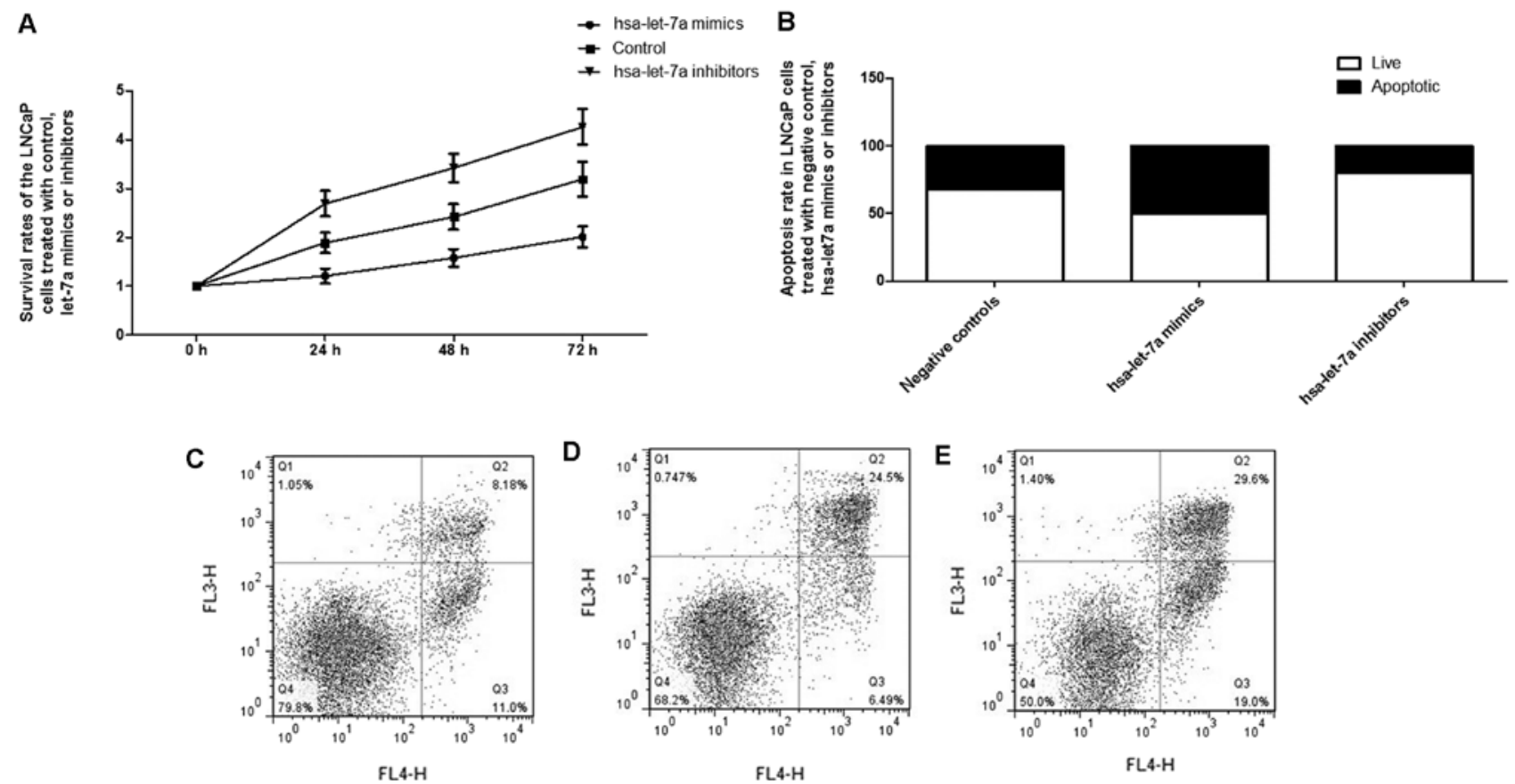

Figure 6. Effect of let-7a expression alternation on the survival of prostate cancer cells cells. (A) Survival rate comparison between the LNCaP cells transfected with negative control, let-7a mimics or inhibitors. (B) Summary of apoptotic rate in the LNCaP cells transfected with the negative control, let-7a mimics or inhibitors. Apoptotic rate in the LNCaP cells transfected with (C) let-7a inhibitors, (D) negative control and (E) let-7a mimics.

predict the pathological stage of the tumor and the treatment efficiency include primary tumor stage, serum PSA level and biopsy Gleason scores; however, none of these indicators are reliable to predict the clinical outcomes of PCa $(35,36)$. Recurrence is the main cause of fatality for PCa patients and CSCs are proposed to have important roles in cancer recurrence (37). In the present study, confirmatory RT-qPCR was performed to evaluate the expression levels of 6 candidate miRNAs that have been shown to be differentially expressed in prostate CSCs based on microarray analysis in a previous study (32), and identified that let-7a was substantially downregulated in recurrent compared with non-current $\mathrm{PCa}$.

First identified in Caenorhabditis elegans, let-7 has been intensively studied. The human let-7 family is composed of 9 members, which are let-7a, let-7b, let-7c, let-7d, let-7e, let-7f, let-7g, let-7i and miR-98. The let-7 family is generally believed to function as a tumor suppressor by targeting certain known oncogenes, such as Ras (38), high-mobility group A2 (39) and c-myc (40). Downregulated let-7 expression has been identified in numerous cancers, including PCa (41), and it has been associated with poor patient prognosis in lung cancer (42), head and neck squamous cell carcinoma (43), and ovarian cancer (44). Furthermore, let-7 family members have been shown to be involved in the control of the self-renewal capacity of breast cancer cells (45) by regulating the genes, such as Oct4 and Sox 2 , which have been functionally associated with the stem cell (46). Accumulative evidence showed that let-7 could alter the expression of Lin28 and In28B, which in turn block the accumulation of mature let-7, forming a feedback loop and having a critical role in regulating 'stemness' by controlling self-renewal (47-51), and such stemness and self-renewal are the biological characteristics of CSCs that are associated with tumor aggressiveness and recurrence.
As an important member of the let-7 family, let-7a has been shown to fulfill tumor-suppressive functions by suppressing certain CSC properties in PCa (4), as well as in certain other cancer types $(45,52)$. In the present study, let-7a was found to virtually target IGF1R, a gene that has been shown to promote proliferation of variable types of cells by inhibiting apoptosis (53), and such an miR-gene association was confirmed by the luciferase assay, as well as 'loss-of-function' and 'gain-of-function' analysis by transfecting let-7a mimics and inhibitors, respectively.

The inability of a cell to regulate its growth and proliferation is an important characteristic of cancer. Activation of insulin-like growth factor 1 (IGF1)/IGF1R signaling is reportedly critical for PCa cell growth and progression. IGF1 is a universal factor exhibiting pleiotropic effects on a variety of cell types, and IGF1R is a receptor tyrosine kinase that mediates IGF1-induced signaling events, including cell survival and proliferation. The IGF1/IGF1R signaling pathway has an important role in the development and growth of numerous tissues $(1,2)$. In the mammary gland, IGF1 is the primary mediator of growth hormone signaling and controls ductal development and terminal end bud formation (54). Pacher et al (55) reported that activation of the IGF1/IGF1R signaling pathway promoted the expression of a wide spectrum of genes, contributing to the stimulatory effects of IGF signaling on the global protein synthesis rate, cell proliferation and tumor formation.

IGF1, as one of the growth factors and cytokines that control apoptosis, is a potent survival factor. Introduction of IGF1 could prevent serum deprivation-induced apoptosis by binding its ligand, IGF1R, and activating the signaling pathway, and such an effect was proven to be NO independent (56), indicating a potential role of iNOS in the control of apoptosis by the IGF1/IGF1R pathway. The shrinkage of 
apoptotic cells, resulting from a shortage of cytosolic ions and water in response to apoptosis inducers (57), is an initial prerequisite for apoptosis that antecedes the majority of other morphological alterations during the apoptotic process. Jin et al (58) demonstrated that IGF1/IGF1R have a significant role in the inhibition of cell shrinkage, as well as the attenuation of SD-induced apoptosis, and an iNOS-NO-dependent mechanism accounted for a significant role of the effects of IGF1/IGF1R on the control of cell proliferation.

Results of the present study suggest that upregulation of IGF1R, caused by downregulation of let-7a, could promote the proliferation of cancer cells by inducing an increase in the expression level of iNOS and concentrations of NO and cGMP. Consistently, downregulation of IGF1R by upregulation of let-7a could significantly suppress the proliferation of PCa cells by suppressing the expression of iNOS and reducing the concentration of NO and cGMP.

Several limitations are recognized in the present study. Firstly, the sample pool recruited in the present study was small, which makes the conclusion drawn from the study statistically limited, and it requires to be interpreted with caution. Secondly, the participants enrolled were all Chinese, and the conclusion could be further limited by the lack of diversity of ethnicity. Future large-scale investigations involving populations of other ethnicities are therefore warranted to confirm these findings and to evaluate ethnic differences.

In conclusion, the present findings that let-7a directly targets IGF1R in PCa cells could further reveal the mechanism of prostate recurrence. let-7a may partly contribute to IGF1R overexpression in recurrent $\mathrm{PCa}$, by increasing cell survival and proliferation. let-7a may be a novel therapeutic candidate to prevent recurrent $\mathrm{PCa}$ given its ability to induce apoptosis and inhibit cell growth.

\section{Acknowledgements}

The project was fully sponsored by the National Natural Science Foundation of China with grant no. 30371825.

\section{References}

1. Siegel R, Naishadham D and Jemal A: Cancer statistics, 2012. CA Cancer J Clin 62: 10-29, 2012.

2. Siddiqui SA, Inman BA, Sengupta S, Slezak JM, Bergstralh EJ, Leibovich BC, Zincke $\mathrm{H}$ and Blute ML: Obesity and survival after radical prostatectomy: A 10 -year prospective cohort study. Cancer 107: 521-529, 2006.

3. Nolan T and Cogoni $\mathrm{C}$ : The long hand of the small RNAs reaches into several levels of gene regulation. Biochem Cell Biol 82: 472-481, 2004

4. Liu C, Kelnar K, Vlassov AV, Brown D, Wang J and Tang DG: Distinct microRNA expression profiles in prostate cancer stem/progenitor cells and tumor-suppressive functions of let-7. Cancer Res 72: 3393-3404, 2012.

5. Duan Z, Choy E, Harmon D, Liu X, Susa M, Mankin H and Hornicek F: MicroRNA-199a-3p is downregulated in human osteosarcoma and regulates cell proliferation and migration. Mol Cancer Ther 10: 1337-1345, 2011.

6. Duan Z, Choy E, Nielsen GP, Rosenberg A, Iafrate J, Yang C, Schwab J, Mankin H, Xavier R and Hornicek FJ: Differential expression of microRNA (miRNA) in chordoma reveals a role for miRNA-1 in Met expression. J Orthop Res 28: 746-752, 2010

7. Ratert N, Meyer HA, Jung M, Mollenkopf HJ, Wagner I, Miller K, Kilic E, Erbersdobler A, Weikert S and Jung K: Reference miRNAs for miRNAome analysis of urothelial carcinomas. PLoS One 7: e39309, 2012.
8. Lang MF, Yang S, Zhao C, Sun G, Murai K, Wu X, Wang J, Gao H, Brown CE, Liu X, et al: Genome-wide profiling identified a set of miRNAs that are differentially expressed in glioblastoma stem cells and normal neural stem cells. PLoS One 7: e36248, 2012.

9. Akao Y, Nakagawa Y, Hirata I, Iio A, Itoh T, Kojima K, Nakashima R, Kitade $Y$ and Naoe T: Role of anti-oncomirs miR-143 and -145 in human colorectal tumors. Cancer Gene Ther 17: 398-408, 2010.

10. Johnson SM, Grosshans H, Shingara J, Byrom M, Jarvis R, Cheng A, Labourier E, Reinert KL, Brown D and Slack FJ: RAS is regulated by the let-7 microRNA family. Cell 120: 635-647, 2005.

11. Le MT, Teh C, Shyh-Chang N, Xie H, Zhou B, Korzh V, Lodish HF and Lim B: MicroRNA-125b is a novel negative regulator of p53. Genes Dev 23: 862-876, 2009.

12. Zhang Y, Gao JS, Tang X, Tucker LD, Quesenberry P, Rigoutsos I and Ramratnam B: MicroRNA 125a and its regulation of the p53 tumor suppressor gene. FEBS Lett 583: 3725-3730, 2009.

13. Garzon R, Marcucci G and Croce CM: Targeting microRNAs in cancer: Rationale, strategies and challenges. Nat Rev Drug Discov 9: 775-789, 2010.

14. Bader AG, Brown D and Winkler M: The promise of microRNA replacement therapy. Cancer Res 70: 7027-7030, 2010.

15. Fendler A, Jung M, Stephan C, Honey RJ, Stewart RJ, Pace KT, Erbersdobler A, Samaan S, Jung K and Yousef GM: miRNAs can predict prostate cancer biochemical relapse and are involved in tumor progression. Int J Oncol 39: 1183-1192, 2011.

16. Leite KR, Tomiyama A, Reis ST, Sousa-Canavez JM, Sañudo A, Dall'Oglio MF, Camara-Lopes LH and Srougi M: MicroRNA-100 expression is independently related to biochemical recurrence of prostate cancer. J Urol 185: 1118-1122, 2011.

17. Long Q, Johnson BA, Osunkoya AO, Lai YH, Zhou W, Abramovitz M, Xia M, Bouzyk MB, Nam RK, Sugar L, et al: Protein-coding and microRNA biomarkers of recurrence of prostate cancer following radical prostatectomy. Am J Pathol 179: 46-54, 2011.

18. Schaefer A, Jung M, Mollenkopf HJ, Wagner I, Stephan C, Jentzmik F, Miller K, Lein M, Kristiansen G and Jung K: Diagnostic and prognostic implications of microRNA profiling in prostate carcinoma. Int J Cancer 126: 1166-1176, 2010.

19. Spahn M, Kneitz S, Scholz CJ, Stenger N, Rüdiger T, Ströbel P, Riedmiller H and Kneitz B: Expression of microRNA-221 is progressively reduced in aggressive prostate cancer and metastasis and predicts clinical recurrence. Int J Cancer 127: 394-403, 2010.

20. Tong AW, Fulgham P, Jay C, Chen P, Khalil I, Liu S, Senzer N, Eklund AC, Han J and Nemunaitis J: MicroRNA profile analysis of human prostate cancers. Cancer Gene Ther 16: 206-216, 2009.

21. Mackillop WJ, Ciampi A, Till JE and Buick RN: A stem cell model of human tumor growth: Implications for tumor cell clonogenic assays. J Natl Cancer Inst 70: 9-16, 1983.

22. Bonnet D and Dick JE: Human acute myeloid leukemia is organized as a hierarchy that originates from a primitive hematopoietic cell. Nat Med 3: 730-737, 1997.

23. Al-Hajj M, Wicha MS, Benito-Hernandez A, Morrison SJ and Clarke MF: Prospective identification of tumorigenic breast cancer cells. Proc Natl Acad Sci USA 100: 3983-3988, 2003.

24. Singh SK, Hawkins C, Clarke ID, Squire JA, Bayani J, Hide T, Henkelman RM, Cusimano MD and Dirks PB: Identification of human brain tumour initiating cells. Nature 432: 396-401, 2004.

25. Li C, Heidt DG, Dalerba P, Burant CF, Zhang L, Adsay V, Wicha M, Clarke MF and Simeone DM: Identification of pancreatic cancer stem cells. Cancer Res 67: 1030-1037, 2007.

26. Yang ZF, Ho DW, Ng MN, Lau CK, Yu WC, Ngai P, Chu PW, Lam CT, Poon RT and Fan ST: Significance of CD $90^{+}$cancer stem cells in human liver cancer. Cancer Cell 13: 153-166, 2008.

27. Collins AT, Berry PA, Hyde C, Stower MJ and Maitland NJ: Prospective identification of tumorigenic prostate cancer stem cells. Cancer Res 65: 10946-10951, 2005.

28. Sugihara E and Saya H: Complexity of cancer stem cells. Int J Cancer 132: 1249-1259, 2013

29. Freitas DP, Teixeira CA, Santos-Silva F, Vasconcelos MH and Almeida GM: Therapy-induced enrichment of putative lung cancer stem-like cells. Int J Cancer 134: 1270-1278, 2014.

30. Ratajczak M, Tarnowski M, Staniszewska M, Sroczynski T and Banach B: Mechanisms of cancer metastasis: Involvement of cancer stem cells? Minerva Med 101: 179-191, 2010.

31. Chen X, Rycaj K, Liu X and Tang DG: New insights into prostate cancer stem cells. Cell Cycle 12: 579-586, 2013. 
32. Rane JK, Scaravilli M, Ylipää A, Pellacani D, Mann VM, Simms MS, Nykter M, Collins AT, Visakorpi T and Maitland NJ: MicroRNA expression profile of primary prostate cancer stem cells as a source of biomarkers and therapeutic targets. Eur Urol 67: 7-10, 2015.

33. Livak KJ and Schmittgen TD: Analysis of relative gene expression data using real-time quantitative PCR and the 2(-Delta Delta C(T)) Method. Methods 25: 402-408, 2001.

34. Han M, Partin AW, Zahurak M, Piantadosi S, Epstein JI and Walsh PC: Biochemical (prostate specific antigen) recurrence probability following radical prostatectomy for clinically localized prostate cancer. J Urol 169: 517-523, 2003.

35. Brookman-Amissah N, Nariculam J, Freeman A, Willamson M, Kirby RS, Masters JR and Feneley MR: Allelic imbalance at 13 q14.2 approximately q14.3 in localized prostate cancer is associated with early biochemical relapse. Cancer Genet Cytogenet 179: 118-126, 2007.

36. Barron N, Keenan J, Gammell P, Martinez VG, Freeman A, Masters JR and Clynes M: Biochemical relapse following radical prostatectomy and miR-200a levels in prostate cancer Prostate 72: 1193-1199, 2012

37. Li X, Liu Y, Chen W, Fang Y, Xu H, Zhu HH, Chu M, Li W, Zhuang $G$ and Gao WQ: TOP2Ahigh is the phenotype of recurrence and metastasis whereas TOP2Aneg cells represent cancer stem cells in prostate cancer. Oncotarget 5: 9498-9513, 2014.

38. Kumar MS, Erkeland SJ, Pester RE, Chen CY, Ebert MS, Sharp PA and Jacks T: Suppression of non-small cell lung tumor development by the let-7 microRNA family. Proc Natl Acad Sci USA 105: 3903-3908, 2008.

39. Mayr C, Hemann MT and Bartel DP: Disrupting the pairing between let-7 and Hmga2 enhances oncogenic transformation. Science 315: 1576-1579, 2007.

40. Kim HH, Kuwano Y, Srikantan S, Lee EK, Martindale JL and Gorospe M: HuR recruits let-7/RISC to repress c-Myc expression. Genes Dev 23: 1743-1748, 2009.

41. Barh D, Malhotra R, Ravi B and Sindhurani P: MicroRNA let-7: An emerging next-generation cancer therapeutic. Curr Oncol 17: $70-80,2010$.

42. Landi MT, Zhao Y, Rotunno M, Koshiol J, Liu H, Bergen AW, Rubagotti M, Goldstein AM, Linnoila I, Marincola FM, et al: MicroRNA expression differentiates histology and predicts survival of lung cancer. Clin Cancer Res 16: 430-441, 2010

43. Childs G, Fazzari M, Kung G, Kawachi N, Brandwein-Gensler M, McLemore M, Chen Q, Burk RD, Smith RV, Prystowsky MB, et al: Low-level expression of microRNAs let-7d and miR-205 are prognostic markers of head and neck squamous cell carcinoma. Am J Pathol 174: 736-745, 2009.

44. Helland $\AA$, Anglesio MS, George J, Cowin PA, Johnstone CN, House CM, Sheppard KE, Etemadmoghadam D, Melnyk N, Rustgi AK, et al; Australian Ovarian Cancer Study Group: Deregulation of MYCN, LIN28B and LET7 in a molecular subtype of aggressive high-grade serous ovarian cancers. PLoS One 6: e18064, 2011.
45. Yu F, Yao H, Zhu P, Zhang X, Pan Q, Gong C, Huang Y, Hu X, Su F, Lieberman J, et al: let-7 regulates self renewal and tumorigenicity of breast cancer cells. Cell 131: 1109-1123, 2007.

46. Kong D, Banerjee S, Ahmad A, Li Y, Wang Z, Sethi S and Sarkar FH: Epithelial to mesenchymal transition is mechanistically linked with stem cell signatures in prostate cancer cells. PLoS One 5: e12445, 2010.

47. Viswanathan SR, Daley GQ and Gregory RI: Selective blockade of microRNA processing by Lin28. Science 320: 97-100, 2008.

48. Yang X, Lin X, Zhong X, Kaur S, Li N, Liang S, Lassus H, Wang L, Katsaros D, Montone K, et al: Double-negative feedback loop between reprogramming factor LIN28 and microRNA let-7 regulates aldehyde dehydrogenase 1-positive cancer stem cells. Cancer Res 70: 9463-9472, 2010.

49. Zhong X, Li N, Liang S, Huang Q, Coukos G and Zhang L: Identification of microRNAs regulating reprogramming factor LIN28 in embryonic stem cells and cancer cells. J Biol Chem 285: 41961-41971, 2010.

50. Ji J and Wang XW: A Yin-Yang balancing act of the lin28/let-7 link in tumorigenesis. J Hepatol 53: 974-975, 2010.

51. King CE, Cuatrecasas M, Castells A, Sepulveda AR, Lee JS and Rustgi AK: LIN28B promotes colon cancer progression and metastasis. Cancer Res 71: 4260-4268, 2011.

52. Peter ME: Let-7 and miR-200 microRNAs: Guardians against pluripotency and cancer progression. Cell Cycle 8: 843-852, 2009.

53. Esquela-Kerscher A, Trang P, Wiggins JF, Patrawala L, Cheng A, Ford L, Weidhaas JB, Brown D, Bader AG and Slack FJ: The let-7 microRNA reduces tumor growth in mouse models of lung cancer. Cell Cycle 7: 759-764, 2008

54. Kleinberg DL, Feldman M and Ruan W: IGF-I: An essential factor in terminal end bud formation and ductal morphogenesis. J Mammary Gland Biol Neoplasia 5: 7-17, 2000.

55. Pacher M, Seewald MJ, Mikula M, Oehler S, Mogg M, Vinatzer U, Eger A, Schweifer N, Varecka R, Sommergruber W, et al: Impact of constitutive IGF1/IGF2 stimulation on the transcriptional program of human breast cancer cells. Carcinogenesis 28: 49-59, 2007.

56. Kang BP, Urbonas A, Baddoo A, Baskin S, Malhotra A and Meggs LG: IGF-1 inhibits the mitochondrial apoptosis program in mesangial cells exposed to high glucose. Am J Physiol Renal Physiol 285: F1013-F1024, 2003.

57. Wei L, Xiao AY, Jin C, Yang A, Lu ZY and Yu SP: Effects of chloride and potassium channel blockers on apoptotic cell shrinkage and apoptosis in cortical neurons. Pflugers Arch 448: 325-334, 2004

58. Jin C, Guo J, Qiu X, Ma K, Xiang M, Zhu X and Guo J: IGF-1 induces iNOS expression via the p38 MAPK signal pathway in the anti-apoptotic process in pulmonary artery smooth muscle cells during PAH. J Recept Signal Transduct Res 34: 325-331, 2014. 